\title{
El discurso anticomunista en las publicaciones del peronismo de derecha
}

\author{
The anticommunist discourse in the publications \\ of right-wing Peronism
}

Juan Luis Besoky

Universidad de La Plata, Argentina

IdIHCS/CONICET

Resumen: Este trabajo se centra en el devenir del discurso anticomunista presente en las publicaciones de la derecha peronista, desde 1960 hasta 1973. A partir de la caída del peronismo en 1955 y con el impacto que comienza a ejercer la Revolución Cubana, empieza a consolidarse una corriente de izquierda dentro del Movimiento que traerá como consecuencia la reactualización del discurso anticomunista por sectores de la derecha. Estos denunciarán la infiltración marxista en el peronismo y promoverán la búsqueda del "esclarecimiento" doctrinal.

Palabras claves: Anticomunismo, Derecha, Peronismo, Nacionalismo

\begin{abstract}
This work focuses on the evolution of the anti-communist discourse present in the publications of the Peronist right, from 1960 to 1973. After the fall of Peronism in 1955 and with the impact that the Cuban Revolution began to exercise, has become a stream of left within the movement that will result in the updating of the anti-Communist discourse by sectors of theright. These will denounce the Marxist infiltration in Peronism and will promote the search for doctrinal "enlightenment".
\end{abstract}

Keywords: Anticommunism, Right, Peronism, Nationalism 


\section{Introducción}

En este artículo analizo el devenir del discurso anticomunista que sostuvo un sector de derecha del peronismo entre 1960 y 1973. Me centro particularmente en las publicaciones realizadas por lo que denomino la derecha peronista, entendiendo a esta como una serie de organizaciones, militantes e intelectuales que actuaron en el interior y en los márgenes del Movimiento Peronista. La expresión "nacional justicialismo" o "peronismo ortodoxo" también definió a estas agrupaciones, aunque en forma más general designa una cultura política, con la que se referenciaron dichas organizaciones que fueron inscriptas por el mismo Perón, por otras corrientes del peronismo y por otras ajenas a él. El crecimiento de este sector se nutrió tanto del desgajamiento de militantes procedentes de diversas corrientes del nacionalismo de derecha argentino: Alianza de la Juventud Nacionalista y Movimiento Nacionalista Tacuara, que reinterpretaron la naturaleza y posibilidades ofrecidas por el peronismo; así como fue el resultado de la evolución de agrupaciones y figuras que, provenientes del peronismo, incorporaron algunas concepciones del nacionalismo de derecha y resignificaron el proyecto del Movimiento y el rol de su líder. Esta cultura política se caracterizó por la combinación de elementos provenientes de la cultura nacionalista y de otros de origen peronista, siendo sus principales rasgos el énfasis en el nacionalismo, en el revisionismo histórico -con especial hincapié en la figura de Rosas-, un marcado antisemitismo y anticomunismo y cierta preferencia por la acción directa y violenta en su enfrentamiento con la izquierda.

Respecto al discurso anticomunista, señala Lvovich $^{1}$ que la denuncia del comunismo y el combate contra los comunistas reales o imaginarios fue uno de los puntos centrales de la agenda nacionalista en la década de 1930. De esta forma siguió presente en la Alianza Libertadora Nacionalista y en el peronismo desde sus orígenes. Sin embargo, el mismo Perón sostuvo una actitud pragmática frente al comunismo internacional mientras este no interviniera en el escenario local, razón por la cual no tuvo problema en reconocer y comerciar con la URSS a partir de $1946 .^{2}$ A su vez, a

\footnotetext{
${ }^{1}$ LVOVICH, Daniel. Nacionalismo y antisemitismo en la Argentina. Buenos Aires: Ediciones B Argentina, 2003. También analiza esta cuestión ECHEVERRÍA, Olga. Las voces del miedo. Los intelectuales autoritarios argentinos en las primeras décadas del siglo XX. Prohistoria Ediciones, Rosario, 2009.

${ }^{2} \mathrm{Al}$ respecto véase: VÁZQUEZ, Pablo Adrián. «Argentina y URSS. Relaciones comerciales y culturales durante los gobiernos de Perón.» Primer Congreso de estudios sobre el peronismo: La Primera Década. Mar del Plata, 2008.
} 
pesar de considerar al comunismo una ideología extranjera e incompatible con la nacionalidad cristiana, Perón ofreció a la dirigencia comunista un modus vivendi si se abstenía de combatirlo. Esto no era de extrañar ya que según advierte López Cantera ${ }^{3}$, con la llegada de Perón al poder, la lógica comunismo-anticomunismo quedó subordinada a la nueva dicotomía de peronistas versus antiperonistas. Sin embargo, esto no implicó la desaparición del discurso anticomunista que siguió teniendo peso durante el gobierno peronista en organizaciones de la derecha como la Alianza Libertadora Nacionalista.

A partir de la caída del peronismo y con el impacto que comenzó a ejercer la Revolución Cubana, se fue consolidando una corriente de izquierda dentro del Movimiento que trajo como consecuencia la reactualización del discurso anticomunista por sectores de la derecha. Estos denunciaron la infiltración marxista en el peronismo al mismo tiempo que negaban la existencia de una "izquierda nacional". Finalmente, este discurso anticomunista enmarcado en la denuncia de la sinarquía tuvo plena vigencia en los años setenta con la vuelta del peronismo al poder, cuando el enfrentamiento entre la izquierda y la derecha peronista se hizo presente de manera violenta.

El análisis del anticomunismo durante los años sesenta ha recibido la atención de varios investigadores centrados en diferentes organizaciones o tradiciones políticas. Así, trabajos como el de Goebel4 y Galván5 se enfocaron en organizaciones del nacionalismo de derecha como Tacuara o Azul y Blanco, mientras que Ruderer6, Scirica7 y Cersósimo ${ }^{8}$ analizaban diversos aspectos de los actores del campo católico. Por

\footnotetext{
3 LÓPEZ CANTERA, Mercedes. «El anticomunismo argentino en la historiografía (1917-1946).»XII Jornadas Interescuelas/Departamentos de Historia. San Carlos de Bariloche, 2009.

4 GOEBEL, Michael. «A Movement from Right to Left in Argentine Nationalism? The Alianza Libertadora Nacionalista and Tacuara as Stages of Militancy». Bulletin of Latin American Research, 26: 356-377. 2007.

5 GALVÁN, María Valeria. «Influencias de la Guerra Fría en el discurso nacionalista argentino. El retrato de los conflictos internacionales en el semanario nacionalista Azul y Blanco». OPSIS. UFG, (14), 2014

${ }^{6}$ RUDERER, Stephan. «Cruzada contra el comunismo. Tradición, Familia y Propiedad (TFP) en Chile y Argentina». Sociedad y religión (22-38), pp. 79-108. 2012

${ }_{7}$ SCIRICA, Elena. «Núcleos católicos anticomunistas bajo el Onganiato. Encuentros y desencuentros». En Primer Taller de Análisis y Discusión sobre el "Onganiato" (1966-1970), Universidad Nacional de General Sarmiento, Los Polvorines. 2012

${ }^{8}$ CERSÓSIMO, Facundo. «Anticomunistas, nacionalistas y católicos. Trayectorias y redes transnacionales de la militancia contra-revolucionaria argentina en las décadas de 1970 y 1980». En Catolicismos e sociabilidade intelectual na América Latina. Editora da Universidade Federal de Mato Grosso.p. 245 $-271.2013$.
} 
otro lado el sindicalismo "libre" promovido por Estados Unidos fue revisado por Bozza $^{9}$ y los intelectuales "anti-totalitarios", vinculados con Washington por Nállim" ${ }^{10}$.

Justamente este carácter diverso del anticomunismo fue el que llevó a Bohoslavsky y Vicente ${ }^{11}$ a dividir el discurso anticomunista en tres familias basadas en posiciones ideológicas y prácticas políticas diferenciables. La primera se afincaba en una perspectiva católica y nacionalista, y entendía al comunismo como la expresión de una convicción filosófica e ideológicamente errónea, siendo la que mayor contacto presentaba con el peronismo de derecha. La segunda familia estaba anclada en una perspectiva liberal-conservadora y era la que se podía encontrar entre intelectuales, asociaciones empresariales y sindicales, deseosss de combatir el "totalitarismo" soviético. Por último, la tercera familia era de cuño autoritario y estatista y encontraba como punto central a las Fuerzas Armadas. Según los autores, todas ellas cobraron un notable impulso después de 1959 con el miedo a la reproducción del experimento cubano en la región y a que Moscú hiciera de nuevo pie en el continente. Coincide con esta interpretación Scirica ${ }^{12}$ quien advierte que el influjo de la Revolución acentuó expectativas y resquemores en los diversos actores, a la vez que propició nuevas lecturas y estrategias políticas. En este sentido Bozza ${ }^{13}$ ha indagado el impacto de la Nueva Izquierda y la amenaza cubana en las Fuerzas Armadas, la gran prensa, las dirigencias empresariales y eclesiásticas, mientras que Padrón ${ }^{14}$ con un eje similar ha priorizado una mirada comparativa con Brasil.

Sin embargo, en todos estos trabajos se encuentra ausente, por diversas razones, el discurso anticomunista del peronismo de derecha. No sólo el anticomunismo sino la misma existencia de una corriente de derecha dentro del peronismo han reci-

\footnotetext{
9 BOZZA, Juan Alberto. «Trabajo silencioso. Agencias anticomunistas en el sindicalismo latinoamericano durante la Guerra fría». Conflicto social (2-2), pp. 49-75, 2009.

${ }^{10}$ NÁLLIM, Jorge. «Intelectuales y Guerra Fría: el Congreso por la Libertad de la Cultura en Argentina y Chile, 1950-1964». Anuario Del Instituto De Historia Argentina, (14), 2015

${ }^{11}$ BOHOSLAVSKY, Ernesto \& VICENTE, Martín. «Sino el espanto. Temas, prácticas y alianzas de los anticomunismos de derecha en Argentina entre 1955 y 1966». Anuario Del Instituto De Historia Argentina, (14). 2015

12 SCIRICA, Elena. «Comunistas y anticomunistas. Redes políticas y culturales en Argentina y Chile durante la Guerra Fría (circa 1960) ». Anuario Del Instituto De Historia Argentina, (14). 2015.

13 BOZZA, Juan Alberto. «La sombra de la Revolución Cubana. Anticomunismo y nueva izquierda en la Argentina de los primeros años sesenta». IX Jornadas de Sociología de la UNLP, 5 al 7 de diciembre de 2016, Ensenada, Argentina

14 PADRÓN, Juan Manuel. «Anticomunismo, política y cultura en los años sesenta. Los casos de.Argentina y Brasil». Estudios del ISHiR, v. 2, n. 4, pp. 157-73, 2012.
} 
bido poca atención15. En este sentido, el aporte de este artículo radica en recuperar la concepción anticomunista del peronismo y describir las mutaciones del mismo.

\section{Izquierda y derecha en el posperonismo}

Si prestamos atención a los militantes peronistas que integraron el Congreso por la Liberación Nacional en noviembre de 1959 veremos el amplio espectro ideológico que cobijaba el peronismo:

"Allí estaban Cooke, Alicia Euguren y J. J. Hernández Arregui, como expresión de la izquierda; Alberto Ottalagano, fascista convencido; peronistas católicos como Fermín Chávez y Antonio Cafiero; forjistas, como Jorge del Río y Lucas Galigniana; peronistas de derecha, duramente antisocialistas, como Rodolfo Arce; rosistas, como José M. Rosa; peronistas de orígenes socialistas, como Miguel Unamuno, y peronistas de raíces radicales, como Diego Luis Molinari."16

Esta mirada retrospectiva de Galasso nos permite ver las diversas trayectorias políticas que nutrían al peronismo, las cuales no eran óbice para que todas marcharan juntas en pos de lograr el retorno del líder exiliado. Precisamente durante los 18 años que Perón permaneció alejado y su Movimiento perseguido, la lucha por el retorno (de Perón al país y del peronismo al poder) fue la principal división en la sociedad. Sin embargo, este enfrentamiento entre peronismo y antiperonismo produjo otras divisiones al interior del Movimiento. Una de ellas tenía que ver con la capacidad de Perón para mantener su liderazgo. El tipo de autoridad carismática (en sentido weberiano) ${ }^{17}$ que caracterizaba a Perón y su Movimiento se vio amenazada por la "rutinización del carisma" entendida como la burocratización del poder y la emergencia de líderes secundarios que operaban la maquinaria política. Según señalan Arias y García Heras: "Con su líder en el exilio y su partido fuera de la ley, los dirigentes locales peronistas comenzaron a organizar un así llamado ‘Peronismo sin Perón' o neoperonismo para mantener vivas las banderas y alguna participación política.”

Justamente la aparición de dirigentes y partidos neoperonistas dio lugar a la división del Movimiento peronista entre una línea blanda (que confiaba en la forma-

\footnotetext{
15 Sobre esta cuestión véase: BESOKY, Juan Luis Besoky. «La derecha peronista en perspectiva», Nuevo Mundo Mundos Nuevos. Questions du temps présent, 2013.

${ }^{16}$ GALASSO, Norberto. Perón, exilio, resistencia, retorno y muerte (1955-1974). Vol. II. Buenos Aires: Colihue, 2011. p. 878.

${ }^{17}$ Sigo aquí los planteamientos de ARIAS, María F, y RAÚL GARCÍA, Heras. «Carisma disperso y rebelión: los partidos neoperonistas.» En Perón del exilio al poder, de AMARAL, Samuel y BEN PLOTKIN, Mariano, 89-121. Buenos Aires: UNTREF, 2004 [1993] y McGuire, J. W. Perón y los sindicatos: la lucha por el liderazgo peronista. En AMARAL, Samuel y BEN PLOTKIN, Mariano, Ob. Cit,. sobre el peronismo como un tipo de autoridad carismática.
} 
ción de un partido legal y el triunfo en las elecciones) y una línea dura (opuesta a la participación electoral y partidaria de la vía insurreccional). Desde el exilio y con el objetivo de evitar la "dispersión del carisma" Perón se vio obligado a dividir su apoyo entre estos sectores según la coyuntura con el objeto de seguir siendo el único árbitro de su Movimiento.

Junto con el clivaje entre duros y blandos (o intransigentes y conciliadores) comenzó a hacerse visible dentro del Movimiento peronista la otra división (más tenue al principio) entre sectores de izquierda y de derecha. Esta separación, que no necesariamente coincidía en sus límites con la otra, se fue acentuando con el transcurrir de los años hasta volverse el clivaje fundamental con el retorno de Perón al país. Los años ' 60 fueron justamente el inicio de un proceso de ruptura para la resistencia peronista. Según señala el militante y luego integrante del Movimiento Revolucionario Peronista (MRP), Armando Jaime:

“...la resistencia nos igualaba a todos, en el sentido de que podíamos estar trabajando junto a un tipo de derecha. Más tarde hubo una cierta diferencia de concepciones. (...) a partir de 1958, quizás 1959, cuando se organizaron los grupos de la juventud. Entonces se armaron reuniones, plenarios, internas donde surgieron las diferencias. Algunos venían de las corrientes nacionalistas, otros tenían un desarrollo más progresista y algunos tenían alguna influencia de izquierda. Y así como en el peronismo hubo un desarrollo de izquierda interno, propio, también hubo una influencia externa". ${ }^{18}$

Esta influencia externa puede percibirse en el marco de la Guerra Fría y especialmente a partir de las repercusiones de la Revolución Cubana en el peronismo. Para Goebel19, estos hechos intensificaron aún más la polarización entre la izquierda y la derecha dentro del Movimiento, que hasta entonces albergaba tanto a marxistas como a nacionalistas de derecha, todos los cuales podían considerarse peronistas legítimamente mientras no mediara el desalojo explícito de Perón, lo que rara vez ocurría.

La corriente de izquierda dentro del Movimiento dio inicio a lo que varios autores como Bozza $^{20}$ y Raimundo ${ }^{21}$ denominan peronismo revolucionario, entendido

\footnotetext{
${ }^{18}$ BUFANO, Sergio, y ROT, Gabriel. «Entrevista a Armando Jaime.» Lucha Armada en la Argentina, $\mathrm{n}^{\mathrm{o}} 32005$, p. 60 .

19 GOEBEL, Michael. La Argentina partida. Nacionalismos y políticas de la historia. Buenos Aires: Prometeo, 2013. p. 109.

${ }^{20}$ BOZZA, Juan Alberto. «El peronismo revolucionario. Corrientes y experiencias en la radicalización sindical (1958/1968).» Cuestiones de sociología, $\mathrm{n}^{0}$ 3, 2006.

${ }^{21}$ RAIMUNDO, Marcelo. «Acerca de los orígenes del peronismo revolucionario.» historiapolitica.com, s/f. http://historiapolitica.com/datos/biblioteca/raimundo2.pdf
} 
como: "la incorporación del marxismo no sólo como método de análisis de la realidad social sino también como guía para la acción, implicando con esto una profunda resignificación de la ideología peronista.”. Su génesis se dio para los años “6o a través de dos vertientes: una representada por Cooke y su radicalización a raíz de la Revolución Cubana, y otra, más olvidada, desarrollada al calor de las luchas internas del Movimiento Peronista, de la cual el Movimiento Revolucionario Peronista (MRP) fue el caso más emblemático. Cooke fue uno de los más destacados pensadores de lo que se dio en llamar la izquierda peronista o nacional, junto con Juan J. Hernández Arregui, Abelardo Ramos y Rodolfo Puiggrós.

En 1963 se hicieron explícitas las propuestas de la izquierda peronista a través del periódico Compañero que respondía al MRP22. La aparición de este periódico y la propuesta de Cooke de establecer una novedosa vinculación entre peronismo y marxismo, ${ }^{23}$ fue rechazada enfáticamente por diversas figuras y organizaciones del peronismo. Estas fueron parte de un peronismo que se derechizó, al acercarse a los postulados del nacionalismo de derecha, pero también de un nacionalismo que se peronizó. 24

Una de estas organizaciones, que mantenía un fuerte discurso anticomunista, era el Comando de Organización (CdeO) dirigido por Alberto Brito Lima. Este grupo se había convertido para la década de 1960 en uno de los más numerosos del peronismo juvenil, teniendo además la particularidad de estar integrado mayoritariamente por militantes de barriadas humildes de La Matanza y Mataderos. Según testimonia Andrés Castillo, integrante del Operativo Cóndor de 1966 "hay que reconocer que Brito engancha mucha gente en los barrios, grupos 'naturales' de JP, que él los

22 El MRP estaba conformado por una amalgama de sindicalistas duros, sectores juveniles comandados por Gustavo Rearte y elementos de la línea Villalón quien se había definido como castrista. Los unificaba la lealtad a Perón y la oposición a Vandor y se alinearon tras la jefatura de Framini. Posteriormente, a fines de 1964 Perón mismo los desautorizaría a instancias de Vandor, quien se presentó en Madrid ante el General harto de los ataques contra la burocracia sindical. Al respecto véase BOZZA, Ob. Cit.

${ }^{23}$ En una carta que le escribe Cooke a Perón en 1960, insistirá con la pertinencia de utilizar el término izquierda: "De paso, aclaro que aunque la diferenciación entre izquierda y derecha es algo que nos viene de Europa, creo que son términos perfectamente claros, es decir, que no constituyen una diferenciación artificial o intelectualista sino que reflejan un hecho concreto de la vida político social y me confirmo en esa opinión cuando veo que los beatos, militaristas y demás reaccionarios son los más empeñados en negar la existencia de esa diferenciación". Citado en DUHALDE, Luis Eduardo. Correspondencia Perón Cooke. Buenos Aires: Colihue, 2007 p. 471.

$24 \mathrm{Al}$ respecto véase: BESOKY, Juan Luis. La derecha peronista: Prácticas políticas y representaciones (1943-1976) (Tesis de posgrado). Presentada en Universidad Nacional de La Plata. Facultad de Humanidades y Ciencias de la Educación para optar al grado de Doctor en Ciencias Sociales. 2016. 
'bautizaba', les daba un ámbito de discusión dentro del Comando y ya quedaban incorporados a su estructura. El grupo más importante de JP en ese momento era él”. 25

Luego del Congreso de la Juventud Peronista de 1961 se produjo la vinculación de muchos grupos de la JP con los sindicatos, conviertiendose algunos incluso en guardaespaldas o grupos de choque de sindicalistas. El $\mathrm{CdeO}$ estableció estrechos vínculos con la Unión de Obreros Metalúrgicos (UOM) y con el sindicato de la carne en Mataderos. Según relata Hernández Arregui, el 11 de mayo de 1965 el CdeO había participado en la marcha contra la invasión norteamericana a Santo Domingo y el envío de tropas por parte del gobierno de Illia. En esa marcha se produjo la muerte del joven militante Héctor Gatica en un confuso episodio. La derecha peronista responsabilizó al "comunismo" por su asesinato. Respecto a este hecho señala Denaday que el Comando de Organización:

“...protagonizó un enfrentamiento con el Partido Comunista (PC) en la Plaza del Congre-
so, en el marco de la movilización de repudio a la invasión de Santo Domingo por parte de
los Estados Unidos. Puesto que los comunistas habían llegado a un acuerdo con la banca-
da peronista, cuyo jefe era el metalúrgico Paulino Niembro, los comandos hicieron una
manifestación para denunciar lo que consideraban una alianza espuria, acompañados en
esa ocasión por algunos activistas de Tacuara y la Guardia Restauradora Nacionalista. Al
grito de "Caamaño, Perón, Tercera Posición” y "aquí están, estos son, los fusiles de Pe-
rón”, concurrieron con el propósito de romper el acto organizado en conjunto por la Fede-
ración Universitaria de Buenos Aires - dirigida por la izquierda- y la CGT -en manos del
vandorismo-. Así, se desató un enfrentamiento donde resultó asesinado el estudiante
universitario Daniel Grinbank, militante del PC, y el saldo incluyó además una larga lista
de heridos, entre los más graves estaba el comando Héctor Lorenzo Gatica, un obrero fri-
gorífico que finalmente murió el 20 de mayo.”

En el velorio de Gatica se hicieron presentes varias figuras del peronismo de derecha: Brito Lima, los diputados Juan Carlos Cornejo Linares y Edgar Sá, Rodolfo Lombardi (Bases Peronistas Combatientes), Enrique Graci Susini (Sindicato Universitario de Derecho), el Movimiento Nueva Argentina (MNA) y Ángel Delgado que habló por el semanario derechista Retorno. Además hubo ofrendas florales enviadas por Perón, el empresario peronista Jorge Antonio, el neurocirujano Raúl Matera, la Juventud Peronista Comando Organización, la Alianza Libertadora Nacionalista (Movimiento Revolucionario Nacional Justicialista), entre otros. Gatica se convertiría en unos de los mártires del peronismo de derecha en su lucha contra el comunismo.

\footnotetext{
25 HERNÁNDEZ, Pablo José. Patriotas y patriadas. Buenos Aires: Boquerón, 2007. p. 24.

${ }^{26}$ DENADAY, Juan Pedro. «Comando de Organización: un peronismo plebeyo, combativo y nacionalista (1961-1976).» Quinto Sol 20, $\mathrm{n}^{0}$ 1, 2016, p. 9.
} 
En este sentido, advierte Cucchetti, ${ }^{27}$ el CdeO se caracterizó tempranamente por agudizar su enfrentamiento con los militantes comunistas y de izquierda. En este caso, y formado también en una identidad peronista, el activismo político de Brito Lima representó una continuidad entre nacionalismo y anticomunismo. El mismo Brito Lima recordaba su relación personal con los comunistas durante el primer gobierno de Perón:

\begin{abstract}
"Estaban los comunistas. Tenían una biblioteca en la calle Guaminí a dos cuadras de Alberdi. Y esa era comunista, comunista, iban todos los bichos ahí...que a esos les dimos, les dimos una flor de paliza porque se pusieron en contra de Perón. Hicieron un acto a dos cuadras de mi casa, avenida de los Corrales y Guaminí. Ahí vino la yuta, puteaban a Perón y ahí los cagamos. En la época de Perón”. ${ }^{28}$
\end{abstract}

Ladeuix ${ }^{29}$ sostiene una postura similar a la de Cucchetti: si bien la actitud frente a los grupos de la izquierda peronista los ubicaría dentro de la derecha del Movimiento, su acervo ideológico lo acercaba más a los sectores tradicionales del peronismo. Un ejemplo de este anticomunismo puede verse en el testimonio de Jorge Vázquez, militante peronista en Cullen:

\footnotetext{
"Ya durante el año del retorno [1964] Dardo Cabo y Brito Lima agarraron a trompadas y una vez tiros a los "comunistas infiltrados". Brito Lima había sido separado de la Mesa Ejecutiva de la JP por su anticomunismo. Cuestionaba la solidaridad con Argelia y Cuba. Nosotros lo de Argelia lo sacamos en Trinchera desde el principio." ${ }^{30}$
}

Otra de las organizaciones de la derecha peronista era el Movimiento Nueva Argentina (MNA). Conformado a partir de una escisión de la organización nacionalista Tacuara, se había ido acercando al peronismo aunque sin dejar de lado muchos aspectos presentes en aquella. Desde su publicación denominada Nueva Argentina, hacían frecuentes referencias a la amenaza comunista. En de julio de 1965 un artículo titulado "Bases para una estrategia justicialista",31 sostenía que "El marxismo deviene sí un expediente ideológico, un mero instrumento de la estrategia imperial de los nuevos zares rojos". A esto se sumaba el marxismo en manos de China frente a lo cual “Occidente para intentar resistir deberá empezar por armarse ideológicamente ali-

\footnotetext{
${ }_{27}$ CUCCHETTI, Humberto. Combatientes de Perón herederos de Cristo. Buenos Aires: Prometeo, 2010.

${ }^{28}$ ANZALDI, Pablo. «¿Guerra civil en el peronismo? Comando de Organización contra Montoneros en los años setenta.» Instituto de Estudios Estratégicos de Buenos Aires, 2013. p. 9.

29 LADEUIX, Juan Iván. «La mazorca de Perón: prácticas ideológicas de la derecha peronista. Una aproximación a partir de un estudio de caso. Mar del Plata 1970-1976». X Jornadas Interescuelas / Departamentos de Historia, Rosario, 2005.

${ }^{30}$ CULLEN, Rafael. Clase obrera, lucha armada y peronismos. La Plata: De la Campana, 2009. p. 216. ${ }^{31}$ Nueva Argentina, Año IV, No 10, julio de 1965, p. 2.
} 
neándose en torno a una doctrina revolucionaria que a nuestro juicio no puede ser otra que el Justicialismo". Para el MNA el factor tiempo en el plazo inmediato jugaba a favor del Justicialismo, pero en el mediano plazo lo hacía a favor del marxismo. En este sentido concluía que "En la medida que las masas argentinas conserven la fe en el retorno de Perón y en la restauración del Estado Justicialista, permanecerán extrañas al marxismo, pero cuando la pierdan se precipitarán hacia él cómo única tabla de salvación que flota en el mar proceloso del caos y la revolución”. ${ }^{2}$ En un reportaje posterior señalaban rechazar por igual al marxismo y al capitalismo:

\footnotetext{
“-¿Defienden Uds. La sociedad capitalista?

R.-Para nosotros es un sistema contrario a la naturaleza del hombre, originado en las tortuosas mentes del liberalismo materialista para sumir al trabajador en la explotación (...)

- ¿Por qué atacan al marxismo?

R- Porque propugna una forma de supercapitalismo donde la explotación ha sido perfeccionada de modo que sea absoluta y nulas las posibilidades del pueblo de rebelarse contra ella. En síntesis porque es apátrida, ateo y reaccionario. (...)

-¿Por qué atacan Uds. a la sociedad liberal-capitalista?

R- Porque es un orden corrupto e injusto, basado en una concepción individualista que niega al hombre todo destino trascendente." 33
}

A estas organizaciones se sumaron para los años sesenta una serie de publicaciones dirigidas y sostenidas por militantes peronistas con una trayectoria anterior en el nacionalismo de derecha, como Raúl Jassén, o con contactos fluidos con este, como Pedro Michelini y Juan Carlos Cornejo Linares. Estas publicaciones buscaban combatir expresamente los intentos por vincular al peronismo con el marxismo, mediante una labor de "esclarecimiento doctrinario" que rescatara y recordara el carácter nacional, cristiano y anticomunista del peronismo. El análisis de estas publicaciones nos permitirá entender las diversas formas en que se estructuró el discurso anticomunista en el peronismo de derecha.

\section{Las publicaciones de la derecha peronista}

Entre las publicaciones del peronismo de derecha, es posible destacar en primer lugar el semanario Huella, aparecido en La Plata en septiembre de 1963. Este semanario era dirigido por Pedro Michelini, un abogado laboralista platense defensor de presos sindicales, acompañado por Alberto Baldrich. Escribían allí Elías Giménez Vega, Carlos Steffens Soler, José Julio Jáuregui, José María Rosa, Emilio Pasini Cos-

\footnotetext{
${ }^{2}$ Ídem.

33 "Reportaje al MNA" (CPM-Fondo DIPBA, Mesa “A”, Factor político, carpeta 37, legajo 145, folio 8).
} 
tadoat, Julio C. González y Alfredo Gómez Morales, entre otros. Se sostuvo con los ingresos propios de Michelini hasta que por cuestiones económicas debió cerrarlo. Sacó un total de 34 números entre el 10 de septiembre de 1963 y el 2 de octubre de 1964. Empezó saliendo todos los martes para luego hacerlo quincenalmente, siempre de manera gratuita.

Otra publicación de la derecha peronista era Patria Libre dirigida por Susana Valle, hija del general Juan J. Valle fusilado en 1956, y el periodista Fernando García Della Costa, antiguo nacionalista miembro de la ALN. La publicación poseía 16 páginas y tenía un tono más serio en los artículos de las secciones política y economía. Sacó un total de 12 números entre el 14 de marzo de 1963 y el 17 de marzo de 1964, saliendo los primeros 6 en vísperas de las elecciones presidenciales. Fue financiado con el dinero que ganó García Della Costa en una rifa del Club Boca Juniors y dejó de salir cuando este dinero se acabó. Escribieron allí Fermín Chávez, Adolfo Pérez Portillo, Anselmo Pozzi, César Berutti, Rogelio Giordano, José María Rosa, Alberto Baldrich, Enrique Pavón Pereyra, Salvador Nielsen, José Luis Muñoz Aspiru, Oscar Denovi y Juan Carlos Cornejo Linares, entre otros.

En estas publicaciones el anticomunismo, como ha señalado Senkman,34 se vinculaba con el antisionismo y el antisemitismo, ya presente en círculos derechistas del peronismo. Huella publicó el 31 de marzo de 1964 una nota de Raúl Jassén y otra de Andrés Framini en las que acusaban a los sionistas y comunistas de haber robado los legajos de los asesinos de Rosario (haciendo referencia al enfrentamiento entre tacuaristas y comunistas en esa ciudad) y acusaba a la prensa del país de recibir órdenes desde afuera, redactadas en inglés, chino o hebreo. También advertían a los trabajadores, peones y obreros "que no hay solución para sus problemas mientras sigan dominando esas fuerzas (el sionismo racista y militarista) en nuestros centros vitales políticos y económicos". 35 En el No30 de Huella (23/6/1964) advertía "Esta es la opción: PERÓN O COMUNISMO Y CAOS”.

Otra publicación era Patria Bárbara, dirigida por Raúl Jassén y financiada por Jorge Antonio, quien se hallaba exiliado en España. Salió a la luz el 4 de octubre de

34 SENKMAN, Leonardo. El antisemitismo en Agentina/1. Vol. 146. Buenos Aires: Centro Editor de América Latina, 1986. p. 54.

35 Ídem. 
1964 y publicó 14 números hasta 1965. Tuvo una segunda época a partir de 1973. Se definía como una "Publicación independiente de Información Nacional-Justicialista". Como redactores solían aparecer Jaime Lemos, Alberto E. Asseff, Ignacio B. Anzoátegui, Juan Carlos Cornejo Linares, Alberto Baldrich y Gabriel Ruiz de los Llanos. En la revista eran también frecuentes las críticas al judaísmo, el sionismo, el comunismo y "la infiltración en el Movimiento".

Posteriormente se editó Retorno, cuyo primer número salió el 9 de julio de 1964 bajo dirección de José Constantino Barro. Tenía una tirada de 5 mil ejemplares, de distribución gratuita. Luego quedó a cargo de Pedro Michelini hasta abril de 1966 cuando Raúl Jassén asumió la dirección y Jaime Lemos (un correntino que había sido militante de la ALN) asumió como secretario general ${ }^{36}$. Un artículo de la revista Leoplan de mayo de 1965 señalaba que Retorno (entonces dirigido por Raúl Jassén) tenía abiertas simpatías por las concepciones fascistas y era financiado por Jorge Antonio. Los vínculos de Retorno con Jorge Antonio podían verse en los frecuentes editoriales que el empresario solía publicar en el semanario, así como también en la presentación de su libro ¿Y $Y$, ahora qué?, publicitada ampliamente en el $\mathrm{N}^{\circ} 79$ de enero de 1966. El libro, con el autor ausente en España, fue presentado en el Plaza Hotel el 16 de mayo por Alberto Baldrich, Juan Carlos Cornejo Linares y el dirigente gremial de la construcción Carlos Alberto Pereyra. Se hallaban presentes también Pedro Michelini y Bacci, interventor del Partido Justicialista en la Provincia de Buenos Aires.

El carácter marcadamente opositor del semanario al gobierno de Illia, llevó a que Michelini, Jassén y Lemos fueran brevemente detenidos en junio de 1965 por el delito de desacato, al haber publicado un artículo de Jorge Antonio. En marzo de 1966 Retorno pasó de ser un semanario a aparecer dos veces por semana. El último número salió el 15 de julio de 1966 cuando, junto a la revista de humor Tía Vicenta, fueron clausurados por el nuevo gobierno militar de Juan Carlos Onganía. Retorno tuvo una segunda época a partir de julio de 1970, esta vez dirigido por el ex militante del MNA, Edmundo Calabró. Esa etapa contó con reportajes a José Ignacio Rucci y a los "compañeros universitarios peronistas de la CGU", al secretario general de la jun-

\footnotetext{
${ }^{36}$ Señala Carman que muchos redactores provenían del periódico Huella. Aunque se diferenciaban de este en que tenía menos peso las discusiones político-filosóficas, estando Retorno más preocupado por la política coyuntural con el objetivo de agrupar los peronistas detrás del retorno de Perón. En CARMAN, Facundo. El poder de la palabra escrita: revistas y periódicos argentinos: 1955-1976. Buenos Aires: Biblioteca Nacional, 2015, p.589.
} 
ta metropolitana José María Castiñeiras y a los secretarios ejecutivos José Luis Cordero y Ricardo Bernabé Molina.

\section{El peronismo como movimiento nacionalista}

Uno de los temas recurrentes en estas publicaciones era la mención al carácter nacional del peronismo que se resumía en el slogan "Ni yanquis ni marxistas, peronistas". Al mostrarse distante tanto del imperialismo estadounidense como del comunismo soviético el discurso peronista reivindicaba la "tercera posición justicialista”, con la particularidad de que en estas publicaciones la tercera posición asemejaba al peronismo a otros movimientos nacionalistas como el fascismo italiano y el falangismo español.

Estas referencias estaban presentes en la revista Patria Bárbara, Retorno y en los escritos de Juan Carlos Cornejo Linares, quien en su libro Política, Nacionalismo, Estado, luego de comentar las ideas de Maurrás, Mussolini y Hitler, afirmaba que "de todas las concepciones nacionalistas de la preguerra, la más humana, alejada de viciosas exageraciones y ajustada a una visión unitaria y acertada del hombre, el mundo y la sociedad, fue indudablemente, la expuesta por José Antonio Primo de Rivera entre 1933 y 1936”.37. En el mismo sentido se expedía Alberto Baldrich:

\footnotetext{
"Los nacionalismos europeos no son más que las expresiones tradicionales de pueblos que aspiran a vivir con justicia y libertad, de acuerdo a su auténtico ser, y en su propio ámbito geográfico. Cada uno lleva además de esta característica general, sus modalidades regionales e históricas. Así, el nazismo alemán, no es más que la continuación del tradicional socialismo de Estado y de cátedra, y la vocación de liberarse de los tentáculos que lo corrompían y pretendían dominarlo. Lo mismo, y a su modo, fue el fascismo italiano y el falangismo de Primo de Rivera en España."38
}

Patria Bárbara, por ejemplo, rescataba a Benito Mussolini (a quien colocaron en la tapa junto a la frase de Perón: Mussolini es inimitable)39. De esto dirá en el editorial del número siguiente bajo el título "Fieles a nosotros mismos":

PATRIA BARBARA quiere ser como quienes la escriben: fiel a sí misma. Por esto ha dedi-

\footnotetext{
37 CORNEJO LINARES, Juan Carlos. Política, nacionalismo, estado. Buenos Aires, Cruz y Fierro, 1966, p. 71.

38 "Baldrich habla al Estado Mayor: Nacionalismo, Capitalismo y Comunismo" en Patria Bárbara, año I, $\mathrm{N}^{\circ} 2,15$ de octubre de 1964, Buenos Aires, p. 2.

39 Véase "Los Grandes” y el artículo “José Antonio, a 28 años de su fusilamiento" en Patria Bárbara, Año I, $\mathrm{N}^{\circ} 2$, 2da quincena noviembre de 1964, p. 17 y 20; y el análisis a 19 años de la caída del nacionalismo, en Patria Bárbara cuya tapa trae una esvástica, Año I, $\mathrm{N}^{\circ} 5$, primera quincena de diciembre de 1964, p. 7.
} 
cado una tapa a Benito Mussolini y no ha vacilado en mostrar su serena admiración hacia el hombre que, de cualquier modo es una de las cúspides del pensamiento político contemporáneo. Por las mismas razones es fiel al General Juan Domingo Perón y ratifica, cuando todavía es tiempo de hacerlo, que nunca abandonará al Caudillo de la Revolución Nacional Justicialista. 40

En las páginas de Retorno pueden verse los vínculos mantenidos con diferentes sectores de la derecha peronista que compartían y difundían esta cultura política nacionalista como la Escuela Superior de Conducción Política, el MNA, la Alianza Libertadora Nacionalista, el CdeO y la Liga Árabe. Senkman ${ }^{41}$ ubica al periódico $R e-$ torno como hispanista y católico, admirador de las ideas de José Primo de Rivera. Esto último puede verse por ejemplo en el número 79 de enero de 1966, el cual trae una nota de un colaborador español sobre el pueblo y la legitimidad del poder. Se trata de Vicente Marrero Suárez, ideólogo y activista tradicionalista carlista español, vinculado al Opus Dei. Los números 91 y 92 de marzo de 1966 saludaron con beneplácito la llegada a Argentina de Carmen Franco Polo, hija de Franco, "quien realizara en España una tarea de acción social similar a la desplegada por Evita en la Argentina”. El artículo finaliza exclamando: "iVIVA LA ARGENTINA! iARRIBA ESPAÑA! ¡VIVA HISPANOAMÉRICA UNIDA EN LA FE, EN ESPAÑA y EN EL IDEARIO NACIONAL-JUSTICIALISTA! iVIVA FRANCISCO FRANCO! iVIVA PERÓN!”. ${ }^{2}$

Retorno mostraba un alineamiento directo con María Estela Martínez de Perón, argumentando que quienes desconocían a la delegada del comando superior traicionaban a Perón. En el No 66 del 13 de octubre de 1965 Retorno le da la bienvenida a Isabel Martínez de Perón como mensajera del general. Luego del golpe de Onganía, sacaron un artículo donde decían:

\footnotetext{
"El pueblo peronista, junto a su único jefe y caudillo Gral. Perón, saluda a la Revolución Argentina, que puso fin al régimen de vergüenza e inmoralidad del liberal-marxismo y manifiesta su esperanza de que la síntesis Pueblo-Ejército conduzca a la Patria hacia su grandeza definitiva". 43
}

\section{La "infiltración marxista" en el Movimiento}

Otro de los temas recurrentes en las publicaciones era la influencia que el mar-

\footnotetext{
40 Patria Bárbara, año I, $\mathrm{N}^{0} 5$, 1ra quincena diciembre de 1964, p. 3.

${ }^{41}$ SENKMAN, Leonardo. El antisemitismo en Agentina/1. Vol. 146. Buenos Aires: Centro Editor de América Latina, 1986. p. 296.

42 Véase también el artículo: “iPresente! Argentino a José Antonio" en Retorno, Año II, $\mathrm{N}^{\circ} 72,24$ de noviembre de 1965 , p. 3 .

43 Retorno, $\mathrm{N}^{\circ} 109,2$ de julio de 1966. Citado en (Carman 590).
} 
xismo, en sus diversas variantes, comenzaba a ejercer en el peronismo. Para la derecha peronista este proceso se trataba claramente de una infiltración comunista que buscaba alterar su esencia. Así, en el editorial del $\mathrm{N}^{\circ} 4$ de Patria Bárbara, se sostenía que:

“...el periódico Compañero, dirigido por el comunista Mario Valotta (director de "Democracia" en tiempos de Frondizi y de los contratos petroleros) que, utilizando términos netamente marxistas (como "conducción burocrática") acusaba a los dirigentes locales de traición a Perón. (...) revela hasta qué punto la infiltración marxista ha penetrado en las filas justicialistas al socaire, quizás, de una conducción que no siempre estuvo a la altura de las circunstancias...”. 44

En Retorno, al igual que en el resto de las publicaciones de la derecha peronista se utilizaban los términos "traidores" e "infiltrados" para referirse a los sectores de izquierda del Movimiento peronista siendo frecuentes las frases: "El Movimiento peronista es incompatible con el marxismo" o "Ni yanquis ni marxistas, peronistas". Un artículo aparecido en el número 36 de marzo de 1965 bajo el título "Votoblanquismo: estigma de traidores e infiltrados" criticaba a aquellos sectores dirigidos por Valota "ex secretario del Socorro Rojo Internacional” que pretenden "orientar al peronismo":

\footnotetext{
"Esta pandilla de pícaros ha conseguido arrastrar algunos elementos que titulándose de línea 'dura' y de la juventud han terminado por ser comparsa de los más recalcitrantes antiperonistas. Pero, por suerte, esta campaña ha caído en el vacío y en el ridículo. Hasta el peronista más lerdo, sabe que los managers del voto en blanco son sirvientes de Frondizi, de Perette o de la DAIA. Sabe que son infiltrados que quisieran confundir al pueblo llevándolo a rodeo ajeno. El peronismo los aplastó a ellos y a sus mandaderos". 45
}

Las notas sobre la infiltración eran permanentes en Retorno, a punto tal que en el número 80 de enero de 1966, traía en tapa el siguiente título: "La escoria roja intenta impedir el retorno del caudillo”. Allí un recuadro sostenía:

\begin{abstract}
"Toda la extensa gama de marxistas, desde los desembozados comunistas pequineses o moscovitas, hasta los 'troskiztas' disfrazados de 'peronistas de izquierda', temblaron ante el anuncio del Retorno del Caudillo a la Patria. Estos enemigos de nuestras Fuerzas Armadas, de la Iglesia católica, de los Sindicatos y de Perón y su Doctrina Justicialista, se pusieron histéricos ante el regreso de nuestro Jefe, pues saben que el mismo importa la concreción de la síntesis pueblo-ejército, y que con él en su suelo, la Argentina retomará su camino de grandeza, del que la apartara la conjura masónica liberal-marxista de la 'revolución libertadora'. No ignora toda esa escoria humana, que la presencia física de Perón entre los argentinos destruirá en forma total y definitiva, todo intento de dominación marxista. Por eso el comunismo ya ha comenzado a trabajar para impedir el retorno de Perón. (...) Por eso desde este Vocero del Peronismo, mangrullo de la Patria gaucha y Justicialista, advertimos a los compañeros de esta sucia maniobra e insistimos con nuestra
\end{abstract}

\footnotetext{
44 Patria Bárbara, año I, $\mathrm{N}^{\circ} 4$, 2 da quincena noviembre de 1964, p. 4.

45 Retorno, año II, $\mathrm{N}^{\mathrm{O}} 36,15$ de marzo de 1965, p. 3.
} 
invariable prédica: SOLO EL RETORNO DE PERON Y LA SÍNTESIS PUEBLOEJERCITO SALVARAN A LA ARGENTINA DE SU TOTAL DESTRUCCIÓN. Quienes se oponen al Retorno del Caudillo, deben ser marcados de ahora en más y para siempre como INFAMES TRAIDORES DE LA PATRIA". 46

En estas citas es posible apreciar que para la derecha peronista la existencia de la izquierda peronista no era un proceso genuino sino una táctica de infiltración del comunismo. A su vez, al negarles su pertenencia al Movimiento rechazaban la posibilidad de que su identidad peronista fuera real por lo cual hablaban de "disfraz de peronistas”. Para Retorno, los llamados al voto en blanco promovidos por la línea dura del peronismo revolucionario, eran una táctica ajena a la voluntad de Perón. Esta no era la única acusación que el periódico hacía a la izquierda. También los englobaba dentro de la "conjura masónica liberal-marxista” ya presente en la Revolución Libertadora, lo cual explicaba el fracaso del Operativo Retorno. Este se debía a que la izquierda peronista en realidad no quería que Perón retornase a la Argentina.

La infiltración del peronismo por parte del marxismo tenía para la derecha peronista varias vertientes. En el tercer número de Patria Bárbara de noviembre de 1964 se reproducía el resumen de un informe "que ha estado circulando en las últimas semanas en los medios justicialistas y nacionalistas" 47 . Allí se acusaba a las organizaciones izquierdistas y algunas colaterales del Partido Comunista (PC) de intentar "crear en la Argentina un fuerte sentimiento antioccidental" y "arrastrar al Justicialismo hacia el marxismo, desubicándolo de su posesión Nacional y Cristiana”. Entre los responsables de este intento de infiltración el informe ubicaba a las diversas escisiones del PC: el núcleo de Pasado y Presente ligado a Juan Carlos Portantiero, la "línea china", el "puigrosismo que dice ser pro-peronista" y "el grupo Real, profrondizista". A éstos se sumaba la "izquierda nacional" a través del Movimiento de Liberación Nacional de Ismael Viñas, el periódico Compañero de Mario Valotta, grupos trotskistas como el de Palabra Obrera de Nahuel Moreno, el Partido Socialista Izquierda Nacional de Abelardo Ramos y el grupo Praxis de Silvio Frondizi. Según Patria Bárbara:

\footnotetext{
"Otros grupos castristas que están tratando de influir al peronismo para teñirlo de rojo son los comandados por John William Cooke y Héctor Villalón (...) La infiltración de los marxistas ha llevado a ciertos elementos de esa filiación a ocupar notorios puestos de asesores en algunas organizaciones gremiales, claramente lanzadas a una política de rompi-
}

\footnotetext{
${ }^{46}$ Retorno, Año III, Nºo, 19 de enero de 1966, p. 1.

47 "Informe de la crisis en el Partido Comunista y la penetración marxista en el Movimiento" en Patria Bárbara, Año I, $\mathrm{N}^{\circ} 3$, 1ra quincena de noviembre de 1964, p.13.
} 
miento de las condiciones de pacificación nacional que Perón quiere para su retorno”.48

En este sentido la derecha peronista rechazaba a la izquierda nacional a la que también veía como un mecanismo de infiltración. De esta forma, en el segundo número de Barricada, publicación de un sector de Tacuara que respondía a Alfredo Ossorio y se identificaba con el peronismo, figuraba un artículo titulado "Un nuevo disfraz. iCuidado con la izquierda nacional! Allí sostenían que:

\begin{abstract}
“...a los marxistas les resulta cada vez más difícil actuar abiertamente. Nadie les da bolilla, salvo algunos intelectualoides de décima categoría, y menos los proletarios que vivieron la época pre-revolucionaria del peronismo. Para poder actuar eficazmente, comunistas y trotskistas tienen que disfrazar su pensamiento y sus propósitos adoptando un ropaje nacionalista. Es lo que hacen entre nosotros, los heterogéneos integrantes de la "Izquierda Nacional". El comunista Astesano, el trotskista Ramos, el frigerista Valotta y el indefinido Hernández Arregui se proclaman peronistas y rosistas, y se infiltra en las organizaciones más nacionales. (...) Por supuesto, al mimetizarse, los marxistas de la "Izquierda Nacional" no renuncian a su doctrina: meramente la camuflan para hacerla aceptable para los militantes nacionalistas que no tienen la formación suficiente para darse cuenta de la trampa que se les arma"49
\end{abstract}

\title{
Del anticomunismo al antimontonerismo, la lucha contra la sinarquía
}

Luego de varios años de proscripción y llegando a su fin el gobierno de facto auto denominado "Revolución Argentina" (1966-1973) se intensificó la apertura electoral. El año 1972 fue testigo de la profundización de las diferencias ya presentes desde hacía tiempo en el Movimiento peronista, entre un ala de izquierda y otra de derecha. La novedad de este nuevo período, que se inició el 25 de mayo de 1973 con el retorno del peronismo al poder mediante la asunción del delegado Héctor Cámpora, fue que el apoyo de Perón a las dos alas del Movimiento cesó. A partir de entonces comenzó el proceso de institucionalización o "depuración” del ala izquierda del peronismo, en la cual la Tendencia Revolucionaria hegemonizada por Montoneros era mayoritaria. En este proceso y sobre todo a partir del Documento Reservado que llamaba a depurar el Movimiento, las organizaciones de la derecha peronista como la Juventud Sindical Peronista (JSP), la Juventud Peronista de la República Argentina (JPRA), la Alianza Libertadora Nacionalista (ALN) y el Comando de Organización (CdeO), junto a diversas publicaciones, apoyaron el accionar anticomunista de los funcionarios peronistas.

\footnotetext{
48 Ídem

49 Barricada, $\mathrm{N}^{\mathrm{O}} 2$, noviembre de 1963 , p.2. La misma nota pero con un lenguaje más violento fue reproducida en "Sindicato. Boletín de la Secretaria de Formación del Comando Mar del Plata. Movimiento Nacionalista Tacuara". Noviembre de 1963, No 4 . (CPM-DIPPBA, Mesa "Referencia", Legajo 10.411, folio 277)
} 
Los meses de octubre y noviembre trajeron también la aparición de varias publicaciones alineadas con la derecha peronista: la revista Alianza, vocera de la ALN, en octubre y, en noviembre, dos publicaciones más: Primicia Argentina y El Caudillo de la Tercera Posición, esta última presentada como vocera del Consejo Superior. En diciembre, Raùl Jassén reemplazó la segunda etapa de Patria Bárbara con otra revista bajo su dirección: Consigna Nacional. En todas estas publicaciones eran frecuentes los ataques, denuncias y amenazas a figuras de la izquierda peronista. La revista El Caudillo de la Tercera Posición era un semanario de información general dirigido por Felipe Romeo. Este era un antiguo militante del Comando $1^{\circ}$ de Mayo de Tacuara, dirigido por Ossorio, que luego se había vinculado al MNA. El Caudillo vio la luz el 16 de noviembre de 1973, cinco días antes de que hiciera su aparición pública la Triple A, para representar la voz de la derecha peronista y contrarrestar la línea editorial de El Descamisado, órgano de prensa de Montoneros. La revista El Caudillo se publicó de manera casi regular hasta fines de 1975 y llegó a vender 9400 ejemplares en los kioscos de la Capital Federal. Una de sus características era el casi total anonimato en el staff, ya que la única firma visible era la de Romeo, y el editorial siempre a doble página, que funcionaba como una bajada de línea de la derecha peronista.

Este período, que ya fue analizado por el autor,50 implicó la reconfiguración del anticomunismo de la década del sesenta en un antimontonerismo. Justamente la denuncia de los infiltrados se dirigía ahora a los sectores englobados en la Tendencia51. Así lo señalaba un militante de la derechista JPRA en una entrevista realizada por El Caudillo:

"La "tendencia" no es peronista, si no, no sería "tendencia", sería JPRA. Los dirigentes
son en su mayoría gorilas provenientes de la clase media intelectualizada del Partido Co-
munista o de los sectores troskos expulsados de todos lados. La gente que los acompaña
se compone de traidores a Perón y de compañeros engañados por los cantos de sirena y
por las reiteradas mentiras gorilas que esgrimen sus dirigentes. En resumen, son enemi-
gos y traidores. Una vez más la JPRA ordena a los compañeros CREER EN PERON,

50 BESOKY, Juan Luis. « "En la patria de Perón, ni judío ni masón". Aproximaciones a la cultura política de la derecha peronista en los años setenta». História e Cultura, Franca, v. 5, n. 3, p. 199-223, 2016. ${ }^{51}$ Así lo recordaba el militante y periodista Raúl Jassén desde Consigna Nacional: "En lo que a mí respecta si es que tiene algún valor todo lo que llevo escrito sobre el tema, puedo certificar que en 1964 traté de llamar la atención de los pseudos dirigentes del Movimiento acerca del tema de la infiltración y de sus métodos. Por ahí deben de andar los ejemplares de "Retorno", que entonces dirigía, ocupándose del tema. (...) Hemos de ser bien claros porque no vivimos tiempos de bonanza. Particularmente he de repetir que se impone una eficaz campaña de depuración ideológica y una consecuente actitud misionera apara propagar la Doctrina de Perón.”. Consigna Nacional, Año I, No $6,2^{0}$ quincena de febrero de 1974, p. 32 


\title{
OBEDECER A PERON Y COMBATIR POR PERON”.52
}

En realidad el antimontonerismo se englobaba dentro de una denuncia más amplia que era la de la sinarquía. Los viejos enemigos de la derecha peronista: comunistas, judíos, sionistas, masones y liberales, entre tantos otros, pasaron a ser englobados en el concepto de "sinarcas" cuya acción mancomunada era lo que los "verdaderos peronistas" debían combatir. Sinarcas hacía referencia a quienes integraban la sinarquía, concepto que se volvió frecuente en los años setenta. Este concepto había sido desarrollado por el intelectual peronista Carlos Disandro desde los años sesenta53. En la revista Frontera 67 dirigida por Raúl Jassén luego de la clausura de $R e-$ torno podía encontrarse la primera mención a la sinarquía que no pertenece a Disandro54. Allí figuraba en la introducción a un texto de José Antonio Palacios (probablemente escrita por Jassén) la siguiente mención:

\begin{abstract}
"La imposición de un gobierno mundial -tal como lo preconiza la sinarquía- no es, ya una lejana abstracción sino una dramática y concreta realidad. Entre nosotros, los argentinos, un puñado de hombres de pensamiento y de políticos de singular talla moral e intelectual -Meinvielle, Cornejo Linares, Baldrich, Di Sandro (sic), Juan Puigbó, entre otros - se han ocupado del tema en la conciencia de que la sinarquía es la potencia supranacional que asfixia nuestra personalidad nacional, continental y universal. (...) es decir, la creación del gobierno universal regido por los poderes del dinero." ${ }_{55}$
\end{abstract}

52 "Creer, obedecer y combatir por Perón” en El Caudillo, Año 2, No 11, 25 de enero de 1974, p. 19.

53 En una carta a Perón, del 24 de julio de 1967, Disandro relataba: “... en ocasión de una disertación mía sobre la Sinarquía, disertación organizada por la Rama Femenina, pudimos conversar largo y tendido con el mayor Alberte, y convinimos algunos aspectos en la labor de esclarecimiento, aspectos que ya están en marcha. Posteriormente el mayor Alberte, por intermedio del grupo juvenil de la Escuela, organizó en Buenos Aires, en el Sindicato de la Alimentación, la conferencia sobre Brasil, el día 21 de julio de 1967. Esta vez fue un éxito rotundo (...) Creo que puedo dar por terminada esta primera etapa, que ha sido dura y trabajosa. He mantenido reuniones de esclarecimiento y conferencias, sobre los aspectos conversados en Madrid, en Córdoba, La Plata, Buenos Aires, Lanús, Temperley, Quilmes, etc. Le he propuesto al mayor Alberte que haga bajar a Buenos Aires a grupos más o menos diestros de gente que pudiera hacer de repetidores: yo les daría una vez al mes una suscinta preparación sobre uno de los temas candentes, y además les entregaría un epítome o resumen que pueda servirles de guía, o eventualmente que pueda ser reproducido y distribuido. (...) Hay en las bases -tanto políticas como sindicales- un ansia de esclarecimiento; pero también un desconocimiento sobre el actual estado de algunas cuestiones fundamentales. Los enemigos, particularmente el gobierno y otros sectores, en especial vaticanistas, han coaligado sus esfuerzos para DERIVAR EL MOVIMIENTO HACIA OTRAS METAS, como Ud. verá, mi General, por el suscinto informe con que cierro esta carta: (...) Ahora nos pondremos a la tarea de publicar y distribuir la conferencia sobre Brasil, como hicimos con la de Toynbee, que ha tenido gran repercusión. Le he entregado además al mayor Alberte una copia del trabajo sobre la Sinarquía, para que proceda según crea conveniente a su difusión. Me ha prometido reproducirlo y distribuirlo. Por lo común en todas las reuniones la gente inquiere sobre esta cuestión, y muchas veces no hay tiempo de detenerse demasiado." (Extraído de: http://perso.wanadoo.es/prensanacional/perondisandro.htm )

54 En realidad el término sinarquía ya era usado en Francia y en México aunque con un sentido diferente. En Argentina ya lo había mencionado Meinvielle ("La sinarquía: otra empresa de subversión mundial" en Azul y Blanco, año III, Buenos Aires, 5 de mayo de 1959). Sin embargo, fue con Disandro que el término sinarquía adquirió una sistematización, centralidad y difusión de la que carecía antes.

55 “Estado mundial y destino nacional" en Frontera 67, Año I, Noº enero de 1967, p. 32. 
En la visión de Disandro, la sinarquía era entendida como "la convergencia radical de principios de poder que obran en el mundo desde los orígenes de la humanidad". La revolución nacional del gobierno peronista había sido abortada por la convergencia de los poderes sinárquicos, dentro de los cuales figuraban actualmente los sectores liberales, jesuitas, la masonería, el judeo-bolchevismo y el catolicismo posconciliar. A esto se sumaban los pseudo-imperios de Estados Unidos y la URSS que buscaban destruir la esencia espiritual del resto de las naciones del mundo. Como se puede apreciar, en la concepción de Disandro se encontraban ampliadas las viejas teorías conspirativas ya presentes en la derecha. La novedad y difusión del término se dio cuando Perón lo utilizó públicamente: en su libro La Hora de los pueblos y en declaraciones a Primera Plana en 1971: "El mundo actual, influenciado por las "grandes internacionales" creadas por los imperia-
lismos, está enfrentando a una sinarquía internacional que ha venido manejándolo. Como
ha sucedido siempre, cuando los pueblos comienzan a recobrar su libertad, grandes mo-
vimientos sociales despiertan con todo el poder e intensidad que las circunstancias les
ofrecen". (Perón, 1968, pág. 117)

Con un total de cinco menciones en las 147 páginas de La Hora de los pueblos esta era la primera vez que Perón utilizaba de manera pública la palabra sinarquía (antes lo había hecho por carta a Disandro). A partir de su incorporación al "vocabulario oficial" del peronismo la palabra sinarquía se difundirá rápidamente y sobre todo entre la derecha peronista.

En el número 5 de El Caudillo del 14 de diciembre de 1973 se explicaba a sus lectores el significado de la palabra sinarquía:

\begin{abstract}
“¿Qué es pues, la sinarquía? Podríamos decir, aventurando una definición, que es la unidad operativa de un conjunto de potencias clandestinas, que en todos los órdenes (político, económico, cultural y religioso) contribuyen a la formación de un gobierno mundial invisible. (...) Sinarquía, pues, en sentido etimológico menta la convergencia radical de principio de poder que gobierna al mundo. Es decir, los poderes visiblemente contrapuestos (syn) en el mundo se coaligan en la sinarquía”.
\end{abstract}

También Queraltó, líder de la Alianza Libertadora Nacionalista (ALN), respondía en una entrevista:

“- ¿El objetivo de la ALN es luchar contra los grupos de izquierda?

- Somos un Movimiento de afirmación categórica de las esencias nacionales, como lo dijéramos en nuestra solicitada del día 4 de agosto, al afirmar esas esencias que, como tales, hacen a la existencia de la Nación Argentina, tenemos que luchar necesariamente contra todas las ideas disgregadoras, de las que el marxismo, como el liberalismo, el capitalismo, no son más que expresiones de un denominador común que es la sinarquía internacio- 
nal”. ${ }^{56}$

Asumiéndose como peronistas los redactores de El Caudillo señalaban que los enemigos de antes eran los mismos de ahora. "Los que antes ponían bombas en la Plaza de Mayo ahora las bombas las ponen disfrazados de barbudos marxistas o de barbudos 'peronistas." Para la revista, la izquierda que en 1945 formó parte de la opositora Unión Democrática ahora reaparecía intentando infiltrarse dentro del peronismo. Los "Gorilas de ayer", eran los “montoneros de hoy, disfraces distintos cubriendo la misma suciedad.”. Más adelante agregaba, en una nota sobre el retorno del cadáver de Eva Perón, "Y así como los del 55 robaron su cadáver, señora, los herederos de la antipatria quieren infructuosamente robar su figura”, en referencia sin duda a la apropiación de la figura de Evita por parte de Montoneros.

El enfrentamiento entre la patria peronista y la patria socialista se convirtió durante el tercer gobierno peronista en la manifestación de dos culturas políticas diferentes y enfrentadas por la lucha hegemónica en el Movimiento. Así Raúl Jassen desde Patria Bárbara decía:

\begin{abstract}
"Enmascarados en un slogan que es ocioso - la patria socialista - la izquierda infiltrada en el Movimiento intenta alterar las bases doctrinarias mismas del peronismo, convirtiendo en algo vergonzante, indigno y anticuado el nombre y la doctrina, aún sin agotar en todas sus posibilidades, de Justicialismo. $\mathrm{O}$, ¿̇por qué no? de Peronismo. Provenientes de sectores universitarios o parauniversitarios, este intento izquierdista de copamiento del peronismo, aunque más inteligente, no hace más que continuar el divorcio entre sectores ilustrados (o parauniversitarios) y clase trabajadora. Si en 1945 la universidad casi en pleno se adscribía a un antiperonismo cerril -época del lema "Libros sí, alpargatas no"si en 1955 sin haber aprendido nada, el estudiantado".57
\end{abstract}

De esta manera la negativa a reconocer la peronización de los jóvenes se presentaba a través de la impugnación de sus orígenes sociales. Los nuevos adeptos eran "imberbes o barbudos de Barrio Norte" a la vez que "los hijos de los comando civiles".

\title{
Conclusión
}

En este artículo he analizado el discurso anticomunista específico del peronismo de derecha dejando de lado las expresiones anticomunistas de otros sectores como la Iglesia Católica, las Fuerzas Armadas o los grupos conservadores. El motivo tiene que ver con el hecho de que estos sectores han recibido mayor atención por par-

56 "Queraltó: la ultraizquierda tiene la culpa" en Panorama, 6 de setiembre de 1973, p. 17.

57 "La 'Patria Socialista': nuevo peronismo sin Perón” en Patria Barbara, Año 9, № ${ }^{15}, 2$ de julio de 1973, Buenos Aires. p. 4. 
te de los académicos en comparación con la escasa atención prestada a la variante nacionalista que se identificaba con el peronismo.

Con la caída del peronismo y debido sobre todo al impacto que comenzaba a generar la revolución cubana, vimos la reaparición de un sector del peronismo preocupado por rescatar los valores nacionalistas, católicos y anticomunistas del Movimiento. En este período, la denuncia de la infiltración, que ya tenía antecedentes durante la década del '5o, mostraba las mutaciones del discurso anticomunista preocupado por la "clarificación doctrinaria" y las desviaciones políticas. A su vez, los intentos por desplazar del peronismo a la izquierda nacional tenían la clara intención de reafirmar el carácter antimarxista del Justicialismo. Este discurso se expresó de manera inorgánica a través de diversas publicaciones y organizaciones que mantenían la denuncia del complot donde judaísmo y comunismo aparecían nuevamente vinculados. Figuras como Jassén, Michelini, Cornejo Linares y Disandro fueron claves en el desarrollo de esta perspectiva anticomunista desde las redes y publicaciones en las cuales participaron.

Para los años setenta, con la vuelta del peronismo al poder, este enfrentamiento predominantemente discursivo pasó a adquirir ribetes cada vez más violentos. El impulso dado por el propio Perón contra los sectores de izquierda del Movimiento, dotó a la derecha peronista del aval necesario para desarrollar sus acciones. En este marco aparecieron nuevas publicaciones que hicieron del antimontonerismo su principal herramienta, aunque no la única. Los variados enemigos de la derecha peronista fueron incluidos dentro del concepto de sinarquía.

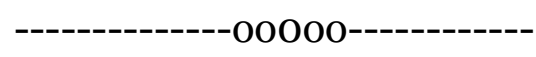

\section{Bibliografía}

ANZALDI, Pablo. “¿Guerra civil en el peronismo? Comando de Organización contra Montoneros en los años setenta." Instituto de Estudios Estratégicos de Buenos Aires, 2013.

ARIAS, María F, y RAÚL GARCÍA, Heras. "Carisma disperso y rebelión: los partidos neoperonistas." En Perón del exilio al poder, de AMARAL, Samuel y BEN PLOTKIN, Mariano, 89-121. Buenos Aires: UNTREF, 2004 [1993].

BESOKY, Juan Luis Besoky. "La derecha peronista en perspectiva», Nuevo Mundo Mundos Nuevos. Questions du temps présent, 2013. 
BESOKY, Juan Luis. “'En la patria de Perón, ni judío ni masón’. Aproximaciones a la cultura política de la derecha peronista en los años setenta”. História e Cultura, Franca, v. 5, n. 3, p. 199-223, 2016.

BESOKY, Juan Luis. La derecha peronista: Prácticas políticas y representaciones (1943-1976) (Tesis de posgrado). Presentada en Universidad Nacional de La Plata. Facultad de Humanidades y Ciencias de la Educación para optar al grado de Doctor en Ciencias Sociales. 2016.

BOHOSLAVSKY, Ernesto \& VICENTE, Martín. "Sino el espanto. Temas, prácticas y alianzas de los anticomunismos de derecha en Argentina entre 1955 y 1966”.Anuario Del Instituto De Historia Argentina, (14).2015

BOZZA, Juan Alberto. "La sombra de la Revolución Cubana. Anticomunismo y nueva izquierda en la Argentina de los primeros años sesenta”. IX Jornadas de Sociología de la UNLP, 5 al 7 de diciembre de 2016, Ensenada, Argentina.

BOZZA, Juan Alberto. "El peronismo revolucionario. Corrientes y experiencias en la radicalización sindical (1958/1968).” Cuestiones de sociología, no 3, 2006.

BOZZA, Juan Alberto. "Trabajo silencioso. Agencias anticomunistas en el sindicalismo latinoamericano durante la Guerra fría”. Conflicto social (2-2), pp. 49-75, 2009.

BUFANO, Sergio, y ROT, Gabriel. "Entrevista a Armando Jaime.” Lucha Armada en la Argentina, $\mathrm{n}^{\mathrm{O}} 32005$.

CARMAN, Facundo. El poder de la palabra escrita: revistas y periódicos argentinos: 1955-1976. Buenos Aires: Biblioteca Nacional, 2015

CERSÓSIMO, Facundo. “Anticomunistas, nacionalistas y católicos. Trayectorias y redes transnacionales de la militancia contra-revolucionaria argentina en las décadas de 1970 y 1980”. En Catolicismos e sociabilidade intelectual na América Latina. Editora da Universidade Federal de Mato Grosso. p. 245-271. 2013 .

CUCCHETTI, Humberto. Combatientes de Perón herederos de Cristo. Buenos Aires: Prometeo, 2010.

CULLEN, Rafael. Clase obrera, lucha armada y peronismos. La Plata: De la Campana, 2009.

DENADAY, Juan Pedro. “Comando de Organización: un peronismo plebeyo, combativo y nacionalista (1961-1976)." Quinto Sol 20, no 1, 2016, p. 9.

DUHALDE, Luis Eduardo. Correspondencia Perón Cooke. Buenos Aires: Colihue, 2007 p. 471.

ECHEVERRÍA, Olga. Las voces del miedo. Los intelectuales autoritarios argentinos en las primeras décadas del siglo XX. Prohistoria Ediciones, Rosario, 2009.

GALASSO, Norberto. Perón, exilio, resistencia, retorno y muerte (1955-1974). Vol. II. Buenos Aires: Colihue, 2011.

GALVÁN, María Valeria. "Influencias de la Guerra Fría en el discurso nacionalista argentino. El retrato de los conflictos internacionales en el semanario nacionalista Azul y Blanco”. OPSIS. UFG, (14), 2014.

GOEBEL, Michael. “A Movement from Right to Left in Argentine Nationalism? The Alianza Libertadora Nacionalista and Tacuara as Stages of Militancy”. Bulletin 
of Latin American Research, 26: 356-377. 2007.

GOEBEL, Michael. La Argentina partida. Nacionalismos y políticas de la historia. Buenos Aires: Prometeo, 2013.

HERNÁNDEZ, Pablo José. Patriotas y patriadas. Buenos Aires: Boquerón, 2007.

LADEUIX, Juan Iván. "La mazorca de Perón: prácticas ideológicas de la derecha peronista. Una aproximación a partir de un estudio de caso. Mar del Plata 19701976”. X Jornadas Interescuelas / Departamentos de Historia, Rosario, 2005.

LÓPEZ CANTERA, Mercedes. "El anticomunismo argentino en la historiografía (1917-1946).” XII Jornadas Interescuelas/Departamentos de Historia. San Carlos de Bariloche, 2009.

LVOVICH, Daniel. Nacionalismo y antisemitismo en la Argentina. Buenos Aires: Ediciones B Argentina, 2003.

MCGUIRE, James. Perón y los sindicatos: la lucha por el liderazgo peronista. En AMARAL, Samuel y BEN PLOTKIN, Mariano, 89-121. Buenos Aires: UNTREF, 2004 [1993].

NÁLLIM, Jorge. "Intelectuales y Guerra Fría: el Congreso por la Libertad de la Cultura en Argentina y Chile, 1950-1964". Anuario Del Instituto De Historia Argentina, (14), 2015.

PADRÓN, Juan Manuel. "Anticomunismo, política y cultura en los años sesenta. Los casos de Argentina y Brasil”. Estudios del ISHiR, v. 2, n. 4, pp. 157-73, 2012.

RAIMUNDO, Marcelo. “Acerca de los orígenes del peronismo revolucionario." historiapolitica.com, s/f.

RUDERER, Stephan. "Cruzada contra el comunismo. Tradición, Familia y Propiedad (TFP) en Chile y Argentina”. Sociedad y religión (22-38), pp. 79-108. 2012.

SCIRICA, Elena. "Comunistas y anticomunistas. Redes políticas y culturales en Argentina y Chile durante la Guerra Fría (circa 1960)”. Anuario Del Instituto De Historia Argentina, (14). 2015.

SCIRICA, Elena. "Núcleos católicos anticomunistas bajo el Onganiato. Encuentros y desencuentros». En Primer Taller de Análisis y Discusión sobre el "Onganiato” (1966-1970), Universidad Nacional de General Sarmiento, Los Polvorines. 2012.

SENKMAN, Leonardo. El antisemitismo en Agentina/1. Vol. 146. Buenos Aires: Centro Editor de América Latina, 1986.

VÁZQUEZ, Pablo Adrián. "Argentina y URSS. Relaciones comerciales y culturales durante los gobiernos de Perón." Primer Congreso de estudios sobre el peronismo: La Primera Década. Mar del Plata, 2008.

\section{Fuentes}

Azul y Blanco, año III, Buenos Aires, 5 de mayo de 1959.

Barricada, $\mathrm{N}^{\circ} 2$, noviembre de 1963.

Consigna Nacional, año I, $\mathrm{N}^{\circ} 6,2^{\circ}$ quincena de febrero de 1974.

CPM-DIPPBA, Mesa "Referencia”, Legajo 10.411, folio 277.

CPM-Fondo DIPBA, Mesa “A”, Factor político, carpeta 37, legajo 145, folio 8. 
El Caudillo, año 2, $\mathrm{N}^{\circ} 11,25$ de enero de 1974.

Frontera 67, año I, $\mathrm{N}^{\circ} 1$, enero de 1967.

Nueva Argentina, año IV, $\mathrm{N}^{\circ}$ 10, julio de 1965.

Panorama, s/n, 6 de setiembre de 1973.

Patria Bárbara, año 9, $\mathrm{N}^{0} 15$, 2 de julio de 1973.

Patria Bárbara, año I, $\mathrm{N}^{\circ} 2$, 2da quincena noviembre de 1964.

Patria Bárbara, año I, $\mathrm{N}^{\circ} 3$, 1ra quincena de noviembre de 1964 .

Patria Bárbara, año I, $\mathrm{N}^{\circ} 4$, 2da quincena noviembre de 1964.

Patria Bárbara, año I, $\mathrm{N}^{\circ} 5$, 1ra quincena diciembre de 1964

Patria Bárbara, año I, $\mathrm{N}^{\circ} 5$, primera quincena de diciembre de 1964

Retorno, año II, $\mathrm{N}^{\circ} 36,15$ de marzo de 1965.

Retorno, año II, $\mathrm{N}^{\circ} 72,24$ de noviembre de 1965.

Retorno, año III, $\mathrm{N}^{\circ} 80,19$ de enero de 1966.

Retorno, $\mathrm{N}^{\circ} 109,2$ de julio de 1966.

Sindicato. Noviembre de $1963, \mathrm{~N}^{\circ} 4$. 